\title{
Odporność na korozję powłoki NiCrFeSi obciążonej cieplnie w atmosferze powietrza i w środowisku siarki
}

\author{
Corrosion resistance of a NiCrFeSi coating heat-loaded \\ in atmosphere of air and in sulfur environment
}

\section{Streszczenie}

Praca dotyczy natryskiwanej plazmowo powłoki NiCrFeSi na podłoże ze stali kotłowej (P 250GH). Powłokę obciążano cieplnie $w$ atmosferze powietrza i w środowisku siarki. Obciążenie cieplne wynosiło 2000 cykli. Jeden cykl obejmował: nagrzewanie do temperatury $560{ }^{\circ} \mathrm{C}$ i wygrzewanie w tej temperaturze w czasie 3 minut, chłodzenie do temperatury $300{ }^{\circ} \mathrm{C}$, nagrzewanie do $560^{\circ} \mathrm{C}$ i wygrzewanie w tej temperaturze $\mathrm{w}$ czasie 1,5 minuty oraz chłodzenie do temperatury $150{ }^{\circ} \mathrm{C}$. Efektem obciążeń cieplnych było zmniejszenie grubości powłoki o $39 \mu \mathrm{m}$. Stwierdzono, że siarka dyfundowała w warstwę przypowierzchniową. Tworzące się produkty jej reakcji z niklem i chromem sprzyjały wykruszaniu się składników tej warstwy, które następnie ulegały utlenianiu.

Słowa kluczowe: powłoka NiCrFeSi; natryskiwanie plazmowe; obciążenie cieplne

\begin{abstract}
The paper deals with a NiCrFeSi coating plasmasprayed on a boiler steel (P 250GH) substrate. The coating was heat-loaded in atmosphere of air and in sulfur environment. The heat load comprised 2000 cycles, whereas each of the cycles included: heating up to $560{ }^{\circ} \mathrm{C}$ and soaking at the temperature for 3 minutes; cooling down to $300^{\circ} \mathrm{C}$ and soaking at the temperature for 1.5 minutes; and cooling down to $150^{\circ} \mathrm{C}$. As a result of such thermal cycling, thickness of the coating was reduced by $39 \mu \mathrm{m}$. It has been found that sulfur had diffused into the superficial layer. The occurring products of sulfur reacting with chromium and nickel contributed to spalling of components of the layer which subsequently were subject to oxidation.
\end{abstract}

Keywords: NiCrFeSi coating; plasma spraying; thermal load

\section{Wstęp}

Nakładanie powłok eksploatacyjnych za pomocą natryskiwania cieplnego, a przede wszystkim plazmowego APS i naddźwiękowego HVOF jest powszechnie stosowane do wytwarzania powłok w kotłach fluidalnych [1].

Większość uszkodzeń wymienników ciepła jest spowodowana ubytkiem grubości ścianek rur w wyniku działania środowiska korozyjnego w warunkach obciążeń cieplnych i erozji [2,3].

Z uwagi na to znaczenia nabierają wszystkie prace ukierunkowane na dobór najkorzystniejszego materiału powłok, parametrów procesu technologicznego ich natryskiwania oraz testowanie w warunkach obciążeń cieplnych w atmosferze powietrza i w środowisku zawierającym składniki typowe dla produktów spalania węgla.
W literaturze technicznej wiele uwagi poświęcono powłokom na bazie niklu. Według $[4,5]$ powłoki NiCrBSi z dodatkami innych pierwiastków są korzystne w przypadku ochrony elementów pracujących w warunkach powodujących korozję wysokotemperaturową. Autorzy prac $[6,7]$ sugerują, że wprowadzenie do proszku NiCrFeSiB twardych, wysokotopliwych węglików, np. CrC, WC, VC, TiC, WC-Co znacząco podnosi, obok odporności na korozję wysokotemperaturową, odporność na zużycie erozyjne. W pracach tych mniej uwagi poświęca się mechanizmowi degradacji jej składników mikrostruktury w warunkach obciążeń cieplnych w atmosferze powietrza i w obecności siarki.

Celem pracy było ustalenie mechanizmu zużycia powłoki NiCrFeSi w warunkach cyklicznie zmiennych obciążeń cieplnych w atmosferze powietrza i w środowisku zawierającym siarkę.

Prof. dr hab. inż. Antoni W. Orłowicz; dr hab. inż. Marek Mróz, prof. PRz; dr hab. inż. Mirosław Tupaj, prof. PRz; dr hab. inż. Andrzej Trytek, prof. PRz; mgr inż. Bogdan Kupiec; mgr inż. Magdalena Radoń; mgr inż. Magdalena Jacek; - Politechnika Rzeszowska.

Autor korespondencyjny/Corresponding author:mfmroz@prz.edu.pl 


\section{Materiał i metodyka badań}

Materiał podłoża stanowiły płytki wykonane ze stali kotłowej P 250GH, o składzie chemicznym zawierającym: 0,17\% C, 0,012\% Si, 0,90\% Mn, 0,02\% Cr, 0,015\% Mo, 0,019\% Cu, 0,050\% Al, $0,010 \%$ P, o wymiarach $50 \times 25 \times 4 \mathrm{~mm}$.

Powierzchnię stalowych płytek, odtłuszczono acetonem, a następnie poddano działaniu ścierniwa (korundu o ziarnistości $125 \div 180 \mu \mathrm{m}$ ) w strumieniu powietrza podawanego pod ciśnieniem 6 barów. Dyszę utrzymywano w odległości ok. 1000 mm od powierzchni płytek. Wartość parametru wysokościowego $S_{t}$ (różnicy wysokości pomiędzy linią wzniesień i linią wgłębień) tak przygotowanej powierzchni płytek próbnych wynosiła $S_{t}=31,5 \mu \mathrm{m}$

Materiałem na powłokę był proszek NiCrFeSi. Cząstki proszku o kształcie kulek o rozmiarach $5 \div 48 \mu \mathrm{m}-90 \%$ i rozmiarach $5 \div 30 \mu \mathrm{m}-10 \%$, charakteryzowały się następującym składem chemicznym: $74,6 \% \mathrm{Ni}, 14,4 \% \mathrm{Cr}, 4,9 \% \mathrm{Fe}, 3,9 \% \mathrm{Si}$. Proces natryskiwania plazmowego zrealizowano na stanowisku SULZER METCO, z zastosowaniem następujących parametrów:

- prędkość przesuwu palnika - 160 $180 \mathrm{~mm} / \mathrm{s}$,

- natężenie prądu - $600 \mathrm{~A}$,

- gazy plazmotwórcze - argon $55 \div 60 \mathrm{l} / \mathrm{min}$,

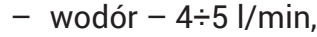

- gaz nośny dla proszku - argon 3 $\div 4 \mathrm{l} / \mathrm{min}$,

- odległość palnika od elementu natryskiwanego - $110 \mathrm{~mm}$,

- rodzaj gazu chłodzącego - powietrze pod ciśnieniem 2 barów.

Jedną płytkę z naniesioną powłoką przeznaczono do badań w stanie wyjściowym. Drugą poddano 2000 cykli obciążeń cieplnych, obejmujących: nagrzewanie do temperatury $560{ }^{\circ} \mathrm{C}$ i wygrzewanie w tej temperaturze w czasie 3 minut, chłodzenie do temperatury $300^{\circ} \mathrm{C}$, nagrzewanie do $560{ }^{\circ} \mathrm{C}$ i wygrzewanie w tej temperaturze w czasie 1,5 minuty oraz chłodzenie do temperatury $150^{\circ} \mathrm{C}$. Co dwusetny cykl powłokę natryskiwano roztworem zawierającym siarkę.

Z płytek z powłoką w stanie wyjściowym i po obciążeniu cieplnym wycięto próbki w płaszczyźnie prostopadłej do powierzchni podłoża i wykonano zgłady metalograficzne.

Pomiary grubości powłoki, badania składu chemicznego i mikrostruktury powłoki wykonano z zastosowaniem mikroskopu skaningowego VEGA XMH, wyposażonego w przystawkę do mikroanalizy składu chemicznego INCA x-act firmy Oxford.
Pomiary grubości powłoki wykonano w pięciu przypadkowych miejscach. Wyniki są średnią wartością z tych pomiarów.

\section{Wyniki badań}

Wyniki badań składu chemicznego składników mikrostruktury powłoki NiCrFeSi w stanie wyjściowym przedstawiono na rysunku 1.

Uzyskane rezultaty wskazują, że w powłoce występują ziarna będące mieszaniną jasnego składnika (pkt. 1) bogatego w nikiel oraz chrom i ciemnego składnika (pkt. 2) bogatego w nikiel, ale zawierającego mniej chromu. Wokół ziaren występują łańcuszki (pkt. 3) bogate w nikiel, chrom i krzem. W powłoce występuje także składnik strukturalny będący mieszaniną składnika bogatego w nikiel, zawierającego podwyższoną zawartość fosforu i krzemu (pkt. 4) oraz składnika uboższego $\mathrm{w}$ fosfor, ale zawierającego więcej chromu (pkt. 5).

Grubość powłoki w stanie wyjściowym wynosiła $254 \pm 12 \mu \mathrm{m}$, natomiast po obciążeniu cieplnym zmniejszyła się do $215 \pm 14 \mu \mathrm{m}$.

Wyniki obserwacji mikrostruktury i analizy składu chemicznego obszaru przypowierzchniowego powłoki NiCrFeSi przedstawiono na rysunku 2.

Obserwacja mikrostruktury i analiza składu chemicznego obszaru przypowierzchniowego powłoki (rys. 2) po obciążeniu cieplnym w atmosferze powietrza i w środowisku zawierającym siarkę, wskazuje na przebieg procesu dyfuzji siarki w głąb powłoki. Transport siarki w głąb powłoki jest blokowany przez łańcuszki składnika strukturalnego (pkt. 7), który ulega zubożeniu w nikiel, chrom i żelazo, ale wzbogaca się $w$ tlen. O skuteczności jego działania świadczy praktycznie brak zmiany składu chemicznego obszaru (pkt. 8) za łańcuszkiem w porównaniu do obszaru pkt 6 na rysunku 1. Obszary nieosłonięte tym składnikiem strukturalnym są narażone na oddziaływanie siarki. Efektem tego jest utworzenie wydzieleń składnika (pkt. 9) bogatego w siarkę, nikiel i chrom w osnowie (pkt. 10) zdecydowanie bogatszej w nikiel, ale uboższej w chrom i siarkę. Jasne obszary (pkt. 11) zalegające jeszcze wyżej to tlenki bogate w chrom i nikiel, a ciemne obszary (pkt. 12) to tlenki bogate w nikiel i chrom.

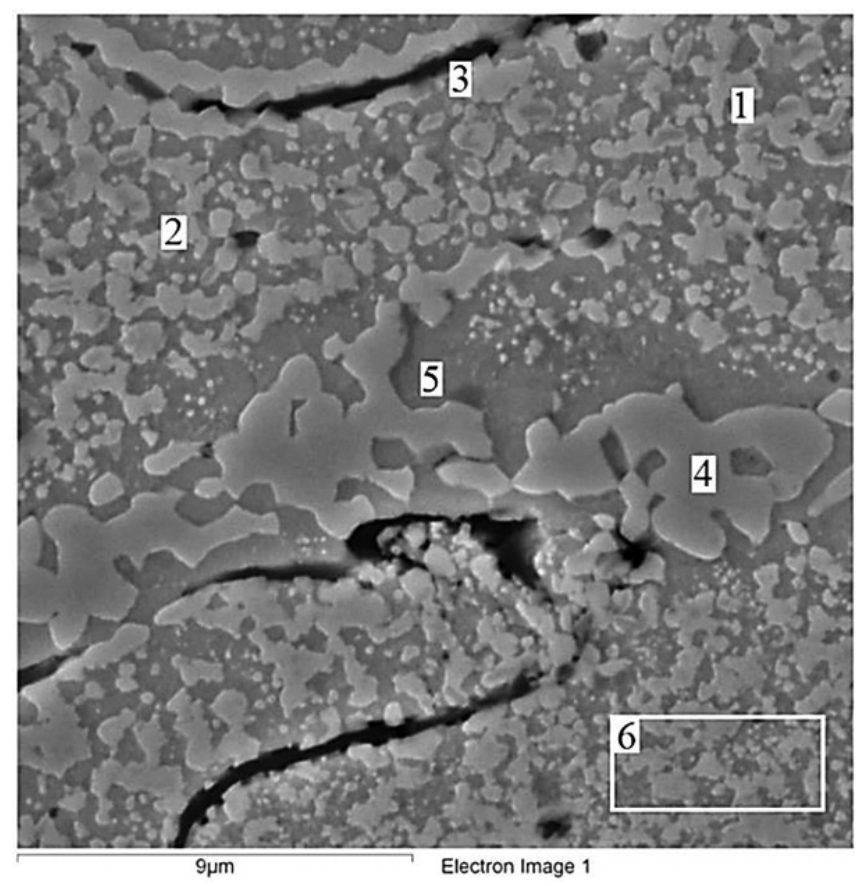

\begin{tabular}{|c|c|c|c|c|c|}
\hline Pkt. & $\mathrm{Si}, \%$ & $\mathrm{P}, \%$ & $\mathrm{Cr}, \%$ & $\mathrm{Fe}, \%$ & $\mathbf{N i} \%$ \\
\hline 1 & 3,05 & 0,00 & 20,21 & 4,37 & 72,37 \\
\hline 2 & 3,57 & 0,00 & 14,77 & 5,50 & 76,17 \\
\hline 3 & 13,82 & 0,00 & 15,71 & 4,39 & 66,08 \\
\hline 4 & 4,54 & 4,20 & 2,41 & 1,25 & 87,59 \\
\hline 5 & 4,40 & 0,21 & 5,97 & 2,47 & 86,93 \\
\hline 6 & 3,01 & 0,00 & 13,35 & 4,65 & 72,65 \\
\hline
\end{tabular}

Rys. 1. Mikrostruktura i skład chemiczny powłoki NiCrFeSi w stanie wyjściowym

Fig. 1. Microstructure and chemical composition of the NiCrFeSi coating in the initial state 


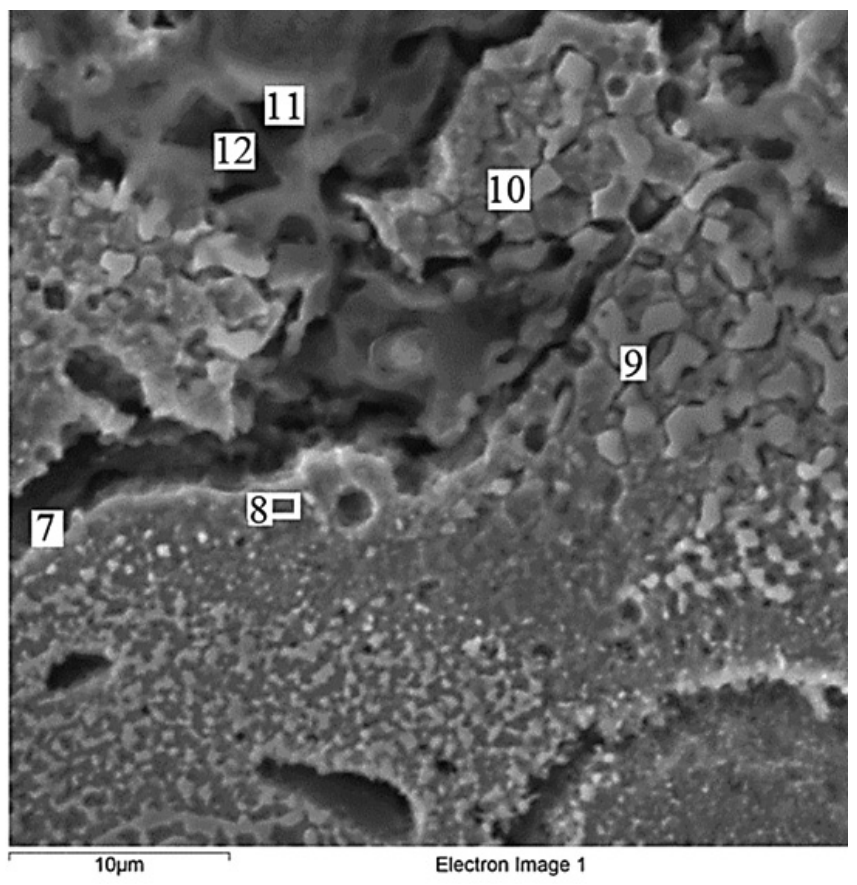

\begin{tabular}{|c|c|c|c|c|c|c|}
\hline Pkt. & $\mathbf{0 , \%}$ & $\mathrm{Si}, \%$ & $\mathbf{S}, \%$ & $\mathrm{Cr}, \%$ & $\mathrm{Fe}, \%$ & $\mathrm{Ni}, \%$ \\
\hline 7 & 24,71 & 13,70 & 0,00 & 12,79 & 2,54 & 43,53 \\
\hline 8 & 0,00 & 2,91 & 0,00 & 12,74 & 4,59 & 74,37 \\
\hline 9 & 0,00 & 0,00 & 31,73 & 33,03 & 1,58 & 27,26 \\
\hline 10 & 0,00 & 0,00 & 1,94 & 9,27 & 3,99 & 79,52 \\
\hline 11 & 27,49 & 0,00 & 0,00 & 31,37 & 5,17 & 19,90 \\
\hline 12 & 25,57 & 0,00 & 0,00 & 8,79 & 1,80 & 58,66 \\
\hline
\end{tabular}

Rys. 2. Mikrostruktura i skład chemiczny obszaru przypowierzchniowego powłoki NiCrFeSi po obciążeniu cieplnym

Fig. 2. Microstructure and chemical composition of the NiCrFeSi coating after thermal loads

\section{Wnioski}

- Uzyskane rezultaty wskazują, że badana powłoka jest wieloskładnikowa. Wyróżnić można mieszaninę składników bogatych w nikiel, w której jasne wydzielenia, w porównaniu do ciemnych, są uboższe w chrom, ale bogatsze w nikiel, mieszaninę składników o wysokiej zawartości niklu, w której jeden jest zdecydowanie uboższy w chrom, ale zawiera również fosfor oraz składnik w postaci łańcuszków bogaty w nikiel, chrom oraz krzem.

- Stwierdzono, że składnik mikrostruktury bogaty w krzem utrudnia dyfuzję siarki i tlenu do powłoki. Składnik ten w trakcie obciążeń cieplnych ulega zubożeniu w nikiel, chrom i wzbogaca się w tlen. W obszarach powłoki nieosłoniętych tym składnikiem mikrostruktury tworzy się mieszanina składników, w której jeden jest silnie wzbogacony siarką i zawiera podobnie wysoką zawartość chromu i niklu, a drugi charakteryzuje się wysoką zawartością niklu i obniżoną zawartością chromu oraz siarki. Ponad tą strefą utworzyła się warstwa tlenków bogatych w nikiel i chrom oraz tlenków bogatych w chrom i nikiel.

- Biorąc pod uwagę uzyskane rezultaty badań stwierdzić można, że powłoka NiCrFeSi nie powinna być zalecana do pracy w warunkach obciążeń cieplnych w atmosferze powietrza i w środowisku siarki.

\section{Literatura}

[1] Radziszewski A., Radziszewski A.: Defects in thermal sprayed coatings occurred during manufacturing and operation, Przegląd Spawalnictwa, nr 9, pp. 42-45, 2012.

[2] Uusitalo M.A., Vuoristo P.M.J., Mäntylä T.A.: Elevated temperature erosion-corrosion of thermal sprayed coatings in chlorine containing environments, Wear, vol. 252, pp. 586-594, 2002.

[3] Szymański K., Hernas A., Moskal G., Myalska H.: Thermally sprayed coatings resistant to erosion and corrosion for power plant boilers - A review, Surface \& Coatings Technology, vol. 268, pp. 153-164, 2015.

[4] Miguel J.M., Guilemany J.M., Vizcaino S.: Tribological study of NiCrBSi coating obtained by different process, Tribology International, vol. 36, pp. 181-187, 2003.
[5] Hurricks P.L.: Some aspects of the metallurgy and wear resistance of surface coatings, Wear, vol. 2, pp. 291-320, 1972.

[6] Wang H., Xia W., Jin Y.: A study on abrasive resistance of Ni-based coatings with a WC hard phase, Wear, vol. 195, pp. 47-52, 1996.

[7] Kulu P., Pihl T.: Selection criteria for wear resistance powder coatings under extreme erosive wear conditions, Journal Thermal Spray Technology, vol. 11, pp. 517-522, 2002. 